\title{
Assembleia de classe como espaço educativo de convivência, autonomia e problematização da realidade ${ }^{1}$
}

Class assembly as an educational space of convenience, autonomy and problematization of reality

La asamblea de classe como espacio educativo para la convivencia, la autonomia y la problematización de la realidad

Mariza Pavan Stucchi - Centro Universitário Salesiano São Paulo - UNISAL | PPGE UNISAL | Americana | SP | Brasil. E-mail: mariza.stucchi@hotmail.com @orcı

Fabiana Rodrigues de Sousa - Centro Universitário Salesiano São Paulo - UNISAL | PPGE UNISAL Americana | SP | Brasil. Contato: fabiana.sante@unisal.br @ ○овсі

Resumo: A problemática da indisciplina e violência tem inquietado educadores e educadoras, instigando-lhes a buscar por novos projetos educacionais, em que a mesma seja entendida como uma questão coletiva da escola. Esse artigo apresenta reflexões tecidas em pesquisa de mestrado que investigou como assembleias de classe podem favorecer o enfrentamento da indisciplina e conflitos escolares vivenciados por adolescentes do Ensino Fundamental. O percurso metodológico foi desenvolvido conforme os tempos da sistematização de experiência preconizados por Oscar Jara-Holliday, que permitiram recuperar, reordenar e avaliar os elementos da prática analisada. Como resultado da sistematização foi possível perceber que a assembleia de classe configura-se como espaço-tempo de diálogo e reflexão sobre a realidade. Ao tomar parte dela, educandos e educadores podem exercitar a escuta atenta e o respeito à diversidade, refletir sobre sua postura e sobre como organizar e expor sua argumentação, construindo coletivamente possibilidades de superar os conflitos escolares.

Palavras-chave: Assembleia de classe. Saberes de experiência. Autonomia.

Abstract: The problem of indiscipline and violence has disturbed educators, leading them to seek for new educational projects, in which the indiscipline is understood as a collective issue of the school. This article presents reflections developed in a master's research that investigated how class assemblies can favor the confrontation of indiscipline and school conflicts experienced by elementary school adolescents. The methodological course was developed according to the times of the systematization of experience recommended by Oscar Jara-Holliday, that allowed us to recover, reorder and evaluate the elements of the practice analyzed. As a result of systematization it was possible realize that the class assembly is configured as a time-space of dialogue and reflection on reality. By taking part in it, learners can exercise a careful listening and respect for diversity, reflect on your behaviour and how to organize and expose their arguments, collectively building possibilities for overcoming school conflicts.

\footnotetext{
${ }^{1}$ Uma versão preliminar deste texto foi apresentada como comunicação oral no Congreso de Educación Salesiana:
} el modelo pedagógico salesiano, em novembro de 2018, na Universidad Politécnica Salesiana, em Quito/Equador.

- Recebido em 20 de fevereiro de 2019 • Aprovado em 19 de setembro 2019 • e-ISSN: 2177-5796

DOI: DOI: http://dx.doi.org/10.22483/2177-5796.2020v22n1p249-270

Copyright @ 2019. Conteúdo de acesso aberto, distribuído sob os termos da Licença Internaonal da CreativeCommons - CC BY-NC-SA Atribuição Não Comercial (https://br.creativecommons.org/licencas/) - Permite distribuição e reprodução, desde que atribuam os devido créditos à publicação, ao autor(es) e que licenciem as novas criações sob termos idênticos. 
STUCCHI, Mariza Pavan; SOUSA, Fabiana Rodrigues de. Assembleia de classe como espaço educativo de convivência, autonomia e problematização da realidade.

Keywords: Class assembly. Knowledge of experience. Autonomy.

Resumen: El problema de la indisciplina y la violencia ha perturbado a los educadores, instándolos a buscar nuevos proyectos educativos, en los que la indisciplina se entiende como un problema colectivo de la escuela. Este artículo presenta reflexiones hechas en una investigación de maestría que investigó cómo las asambleas de clase pueden favorecer la confrontación de la indisciplina y los conflictos escolares experimentados por los adolescentes de la enseñanza primaria. La ruta metodológica se desarrolló de acuerdo con los tiempos de sistematización de la experiencia propugnada por Oscar Jara-Holliday, lo que permitió recuperar, reordenar y evaluar los elementos de la práctica analizada. Como resultado de la sistematización, fue posible percibir que la asamblea de clase está configurada como un espacio-tiempo para el diálogo y la reflexión sobre la realidad. Al participar, los estudiantes y educadores pueden escuchar atentamente y respetar la diversidad, reflexionar sobre su postura y sobre cómo organizar y exponer sus argumentos, construyendo colectivamente posibilidades para superar los conflictos escolares.

Palabras clave: Asanblea de classe. Saber de experiencia. Autonomía. 
STUCCHI, Mariza Pavan; SOUSA, Fabiana Rodrigues de. Assembleia de classe como espaço educativo de convivência, autonomia e problematização da realidade.

\section{Introdução}

A indisciplina escolar tem inquietado educadores e educadoras, instigando-os a buscar por novos projetos educacionais, em que a mesma seja entendida como uma questão coletiva da escola. Pesquisadores como Estrela (2002), Aquino (1996), Rego (1996), Garcia (2006, 2008) têm se debruçado a refletir sobre as consequências da indisciplina e dos conflitos que persistem no cotidiano escolar.

De acordo com Kramer (1994), em sua obra "Por entre as pedras: arma e sonho na escola", a indisciplina e conflitos escolares podem ser apreendidos como pedras-arma ou pedrassonho. A autora diz que uma pedra quebrada se transforma em partes que passam a ter os mais diversos fins (podem ser atiradas contra algo ou alguém), mas quando lapidadas, também podem se transformar em joias raras, há sempre uma possibilidade de mudança, já que todo fragmento de pedra "simboliza a dureza destruída e representa a construção possível" (KRAMER, 1994, p. 13).

Assim, a indisciplina e os conflitos, ao mesmo tempo em que denunciam as dificuldades para efetivação de relações mais horizontais e dialógicas, no interior das escolas; também podem indicar, quando enfrentados com seriedade e problematização, o anúncio de novas possibilidades de organização e humanização das práticas educativas. Repensar as práticas educativas na intenção de humanizá-las exige a escuta atenta acerca do que pensam e sentem as pessoas que vivem a escola diariamente pois:

[...] é imensa a distância entre aquilo que produzimos sobre a escola e a escola real, concreta, essa ali da esquina... E é imensa a defasagem entre o que - das universidades, das secretarias de educação ou de diferentes órgãos públicos e fundações - falamos ou escrevemos para professores e aquilo que transparece da escola e das salas de aula na prática desses mesmos professores. E brutal é a diferença entre o que deles ou para eles falamos e o que - no acontecer diário - eles fazem e de si falam (KRAMER, 1994, p. $11)$.

Destarte, o exercício de lapidar pedras-sonho se faz por meio do diálogo com todos os segmentos que convivem nas instituições de ensino, na intenção de apreender os múltiplos significados atribuídos aos conflitos escolares e as motivações que justificam sua ocorrência. Portanto, faz-se necessário conhecer como tem se dado a convivência no interior das escolas a fim de suscitar contribuições que permitam traçar ações de enfrentamento coletivo a essa problemática da indisciplina. 
STUCCHI, Mariza Pavan; SOUSA, Fabiana Rodrigues de. Assembleia de classe como espaço educativo de convivência, autonomia e problematização da realidade.

No estudo "Convivência, conflitos e educação", Leme (2006) tece um breve histórico das pesquisas que abordaram essa temática no Brasil. A convivência escolar passou a configurar como tema de investigação, a partir de 1980, descortinando a necessidade de compreender as principais modalidades de violência nas escolas, tais como depredação de patrimônio, furtos e roubos, agressões verbais e/ou físicas e verbais, etc. Na década de 1990, verifica-se o "aumento da violência interpessoal entre estudantes, expressa, principalmente, em agressões verbais e ameaças, persistindo a depredação de patrimônio como uma transgressão frequente" (LEME, 2006, p. 7).

Nos anos 2000, outras pesquisas mostram que a crescente exclusão social foi um dos fatores que contribuiu para o aumento da violência dentro das escolas devido ao fato de a criminalidade ser refletida nos espaços escolares, motivada pelas desigualdades entre classes sociais e o consumo desprivilegiado, que causam frustrações nos jovens. Leme (2006) aponta estudos realizados por diversos pesquisadores e pesquisadoras que trazem dados comparativos sobre a manifestação da violência em escolas públicas e privadas. Segundo esses estudos, os perpetradores de atos violentos estão presentes tanto numa como noutra escola, porém, se manifestam de maneira diferente como violência "mais disfarçada em brincadeiras e apelidos na escola privada e mais explícita na pública” (LEME, 2006, p. 8).

A pesquisa de Leme (2006) objetivou investigar como estudantes paulistas do Ensino Fundamental e Médio entendem o convívio na escola em relação à violência, ao seu funcionamento e suas regras, à qualidade das relações interpessoais e às formas de resolução de conflitos utilizadas pela escola. Os resultados apontaram que a violência e o bullying são negativos para o clima escolar. Visando superar esse problema, comumente, as escolas adotam medidas repressoras capazes de responder ao impacto da violência, como a instalação de câmeras, a presença de policiais ao redor do espaço escolar, sanções e punições aos infratores. Todavia, tais medidas, por si só, não solucionam a questão da violência, no interior das escolas, se não forem realizadas concomitantemente com a elaboração de práticas educativas que problematizem as incivilidades e favoreçam o convívio escolar.

Charlot (2002, p. 437) destaca a contribuição de pesquisadores franceses na construção da distinção entre os conceitos de violência, transgressão e incivilidade. Para o autor, essa distinção é útil, pois permite lugares, tratamentos e encaminhamentos diferentes para cada fenômeno. O 
STUCCHI, Mariza Pavan; SOUSA, Fabiana Rodrigues de. Assembleia de classe como espaço educativo de convivência, autonomia e problematização da realidade.

primeiro termo - violência - designa aquilo que "ataca a lei com uso da força ou ameaça usá-la", por exemplo, extorsão, tráfico de drogas, etc. Já o conceito de transgressão alude ao "comportamento contrário ao regulamento interno do estabelecimento (mas não ilegal do ponto de vista da lei)", como não realizar trabalhos escolares, faltar com respeito, dentre outros. E por fim, o vocábulo incivilidade é empregado para designar condutas e comportamentos que se contrapõem às regras da boa convivência, tais como grosserias, ofensas verbais, andar pela sala em momentos inapropriados, cochichar, atribuir apelidos, falta de pontualidade, empurrões, brincadeiras fora de contexto, jogar objetos, gritar, indelicadeza, etc. Essas condutas e atitudes são compreendidas também como microviolências ou pequenas agressões do cotidiano que se repetem com frequência.

As incivilidades são rupturas em nível das regras e expectativas tácitas de convivência, dos pactos sociais que perpassam as relações humanas e cujo sentido muitas vezes supomos seja de domínio público desde a infância. Assim, a conduta incivilizada é criticada pelos professores como ausência da influência educativa da família, por suposta responsável pela socialização primária dos seus filhos e pela sua formação nos esquemas básicos de civilidade (GARCIA, 2006, p. 127).

As incivilidades, segundo a concepção de Garcia (2006), não rompem com acordos, regras e esquemas pedagógicos e sim, rompem com as regras da vida social, ou seja, com o direito de cada um/a ${ }^{2}$ de ser respeitado/a.

A maneira como a escola fará as intervenções em situações de conflito interpessoal poderá refletir na formação dos sujeitos tornando-os mais autônomos quando passam a se conhecer melhor e aprender o de que realmente necessitam para compreender pontos de vistas diferentes do seu, e dessa forma, os conflitos interpessoais são aproveitados, segundo a visão construtivista, como oportunidades de aprendizagem. Deste modo, os sistemas educativos deveriam cumprir com o importante papel de desenvolver as competências necessárias para a formação de cidadãos mais éticos possibilitando a resolução de seus conflitos pessoais e sociais, melhorando a convivência social.

Garcia, Tognetta e Vinha (2013) dizem que é necessário pensar a escola e a relação que se constrói em seu cotidiano entre indisciplina e a cultura escolar. Para tanto, conceituam três

\footnotetext{
${ }^{2}$ Neste texto, adotar-se-á esta grafia para indicar a flexão de gênero em substantivos e adjetivos, a fim de evidenciar a opção política pela afirmação do gênero feminino, em vez de usar somente o masculino conforme normatização da nossa língua portuguesa.
} 
STUCCHI, Mariza Pavan; SOUSA, Fabiana Rodrigues de. Assembleia de classe como espaço educativo de convivência, autonomia e problematização da realidade.

formas de expressão da indisciplina na escola: 1) ausência de identidade entre os critérios e as expectativas assumidas pela instituição escolar no que se refere às atividades pedagógicas e às atitudes dos educandos/as dentro e fora da escola; 2) socialização e relacionamentos construídos pelos/as estudantes em relação aos seus pares e profissionais da instituição escolar no que tange às atividades pedagógicas e à conservação do patrimônio coletivo e, finalmente, 3) o desenvolvimento cognitivo dos/as educandos/as e o que, realmente, eles/as apresentam. Afirmam, ainda, que pode ocorrer resistência ou contestação de educandos e educandas em relação aos esquemas da instituição escolar quando não há uma base democrática que sustente as relações entre estudantes e educadores e os outros adultos envolvidos no processo educativo, podendo reforçar ou gerar conflitos e modos diferentes de indisciplina.

Garcia, Tognetta e Vinha (2013, p. 21) observam que a indisciplina já foi entendida como inadequação dos educandos e educandas em relação à escola, mas ressaltam que a mesma também pode ser apreendida como possibilidade de “[...] expressão da inadequação da própria escola, de suas teorias, métodos e materiais" e da forma como são construídas as relações pedagógicas.

Face ao acima exposto, é possível afirmar a necessidade de que as expectativas dos/as educandos/as, da comunidade e dos/as profissionais da escola sejam compreendidas e consideradas nas relações pedagógicas e que haja contribuição de todos os agentes para a construção de bases democráticas, pois essa construção coletiva pode promover a redução das tensões produzidas pelos/as educandos/as em relação aos contratos e expectativas sociais estabelecidos entre os sujeitos e destes com o conhecimento. Ademais, há que se considerar o fato de que nas escolas em que educandos/as são inseridos/as numa cultura disciplinar da passividade e da obediência, acabam desenvolvendo relações de dependência que impedem o desenvolvimento da criatividade e da voz dos/as educandos/as (VINHA, 2000).

Argumenta-se, aqui, que as assembleias de classe podem configurar-se como prática educativa viável para romper com essa perspectiva da passividade e obediência, constituindo-se como espaços de escuta e de fomento aos poderes e saberes gestados no ambiente escolar, propiciando o momento institucional da palavra, do diálogo, da convivência e de reflexões sobre a alteridade. Esse artigo apresenta reflexões tecidas em pesquisa de mestrado que investigou como assembleias de classe podem favorecer a convivência democrática e o enfrentamento 
STUCCHI, Mariza Pavan; SOUSA, Fabiana Rodrigues de. Assembleia de classe como espaço educativo de convivência, autonomia e problematização da realidade.

coletivo da indisciplina e conflitos escolares vivenciados por adolescentes de duas turmas do oitavo ano do Ensino Fundamental.

\section{Educação dialógica e vivência democrática nas assembleias de classe}

Freire (1996) alerta que o/a educador/a democrático/a não pode legitimar a passividade e as relações de dependência, pelo contrário, seu papel é favorecer a autonomia dos/as educandos/as por meio da rigorosidade metódica.

O educador democrático não pode negar-se o dever de, na sua prática docente, reforçar a capacidade crítica do educando, sua curiosidade, sua insubmissão. Uma de suas tarefas primordiais é trabalhar com os educandos a rigorosidade metódica com que devem se "aproximar" dos objetos cognoscíveis. E esta rigorosidade metódica não tem nada que ver com o discurso "bancário" meramente transferidor do perfil do objeto ou do conteúdo. É exatamente neste sentido que ensinar não se esgota no "tratamento" do objeto ou do conteúdo, superficialmente feito, mas se alonga à produção das condições em que aprender criticamente é possível (FREIRE, 1996, p. 28-29).

Em sua crítica à concepção bancária de educação, Freire (1987) refuta essa perspectiva que se pauta na passividade do/a educando/a que é percebido/a como mero receptáculo de conteúdos, cuja única função seria assimilar depósitos feitos por educadores e educadoras. Ratificando esse entendimento, Aquino (1996, p. 52) reitera que a função social da escola não pode ser reduzida à ação de transferir conhecimentos, mas deve ser entendida como o processo “de fomentar a experiência do sujeito perante a incansável aventura humana de desconstrução e reconstrução" de conhecimentos.

Freire e Shor (1986) refletem sobre a questão do conhecimento, do diálogo, dos fundamentos da educação libertadora e sobre a formação de educadores/as, destacando a importância da transformação do/a educador/a "transmissor/a" de conteúdos para o/a educador/a "libertador/a" e problematizador/a. Os autores supracitados nos ensinam que o/a educador/a democrático/a:

[...] nem manipula, nem lava as mãos da responsabilidade que tem com os alunos. Assume um papel diretivo necessário para educar. Essa diretividade não é uma posição de comando, de "faça isso" ou "faça aquilo", mas uma postura para dirigir um estudo sério sobre algum objeto, pelo qual os alunos reflitam sobre a intimidade de existência do objeto (FREIRE; SHOR, 1986, p. 104). 
STUCCHI, Mariza Pavan; SOUSA, Fabiana Rodrigues de. Assembleia de classe como espaço educativo de convivência, autonomia e problematização da realidade.

Freire (1987) é categórico ao dizer que é por meio do diálogo que as visões de mundo são conhecidas e questionadas, desmistificando ideias e possibilitando novas reflexões. A práxis educativa popular, sustentada por uma concepção dialógica, investe na capacidade de saber ouvir o outro nessa relação de troca de saberes e instiga a construção de novos conhecimentos que proporcionam novas ações. Homens e mulheres são seres da práxis e, como seres do quefazer podem agir sobre o mundo e transformá-lo com suas ações. Assim, o quefazer é ação e reflexão, é práxis balizada pela teoria, para que não caia no verbalismo vazio. Ou seja, para Freire o diálogo promove a autonomia, pois "existir humanamente, é pronunciar o mundo, é modificá-lo. O mundo pronunciado, por sua vez, se volta problematizado aos sujeitos pronunciantes, a exigir deles novo pronunciar” (FREIRE, 1987, p. 78, grifos do autor).

É por meio do diálogo, salienta Freire (1992), que se constrói a consciência crítica da realidade em que se vive, já que ela possibilita a partilha e a problematização das ideias e das experiências, com oportunidades para que todos/as tenham a vez de falar e, da mesma maneira, serem ouvidos/as. O/a educador/a, ao desafiar os/a educandos/as para que apreendam o significado de cada tema ou conteúdo proposto, possibilita que estes/as superem o 'saber de experiência feito'. O autor propõe uma educação que se comprometa com a problematização das situações de vida e das relações do ser humano com o mundo e ela é oposta à educação bancária, na qual se depositam nos/as estudantes os conteúdos escolares.

Uma escola que não oferece condições necessárias à participação e ao diálogo fará com que os sujeitos não consigam conviver e interagir numa sociedade que existe pela palavra e, portanto, dificilmente auxiliará educandos e educandas a alcançarem a própria autonomia. E conquistar a autonomia implica em conscientização e em intervenção no mundo, pois é nesse movimento de busca, junto com outros homens e mulheres, na comunhão e na solidariedade que educandos/as e educadores/as se dirigem ao ser mais, ou seja, à sua autonomia e humanização (FREIRE, 1987).

Dessa maneira, homens e mulheres estão em constante formação durante toda a vida e, por isso, são seres inacabados, inconclusos. É através da práxis, entendida como reflexão e ação sobre o mundo, que os seres humanos tomam consciência de seu inacabamento. Neste contexto, se torna possível afirmar a necessidade do/a educador/a ser criativo/a, crítico/a e suficientemente consciente para exercer o papel daquele/a que instiga a curiosidade, o diálogo e a vontade de 
STUCCHI, Mariza Pavan; SOUSA, Fabiana Rodrigues de. Assembleia de classe como espaço educativo de convivência, autonomia e problematização da realidade.

aprender, possibilitando que o processo de aprendizagem seja de construção e reconstrução do saber ensinado e, garantindo que a metodologia de trabalho seja dialógica em busca de conteúdos programáticos que contribuam com a educação libertadora e democrática.

$\mathrm{O} / \mathrm{a}$ educador/a deve orientar seus educandos e suas educandas para que conheçam o mundo que os rodeia e que, partindo de seus conhecimentos, relacionem os conteúdos aprendidos na escola com a realidade em que vivem, pois "sem rigorosidade metódica não há pensar certo" (FREIRE, 1996, p. 21).

Na contramão dos discursos conservadores do chamado Movimento Escola Sem Partido ${ }^{3}$, Freire e Shor (1986) destacam a impossibilidade da neutralidade na educação, ressaltando que é tarefa da escola e dos/as educadores/as problematizar a realidade em diálogo com os/as educandos/as, por meio de práticas e políticas libertadoras. Ramos e Santoro (2017) denunciam a falácia desse polêmico movimento que apregoa a defesa de uma escola "neutra" e sem “doutrinação política”, ocultando de maneira ardilosa o real objetivo de perpetuar a passividade dos/as educandos/as por meio da manutenção de práticas educativas bancárias centradas na transmissão e reprodução de conteúdos.

Obscurecer a realidade não é ser neutro. Tornar a realidade brilhante, iluminada, também não é ser neutro. Para poder fazer isso, temos que ocupar o espaço das escolas com políticas libertadoras. No entanto, não podemos negar uma coisa muito óbvia. Aqueles que obscurecem a realidade atraves da ideologia dominante, disseminando, multiplicando e reproduzindo a ideologia dominante, estão nadando a favor da corrente! Aqueles que desmistificam a tarefa da reprodução estão nadando contra a corrente! Nadar contra a corrente significa correr riscos e assumir riscos (FREIRE; SHOR, 1986, p. 50)

Freire (1996) nos ensina que educar não é somente transferir conhecimentos, mas ter conscientização, saber usar o bom senso e a ética ao exercer a autoridade docente e não o autoritarismo, caso contrário, esse processo não terá validade. $\mathrm{O}$ autor defende com veemência que a dignidade e a identidade do/a educando/a têm de ser respeitadas, caso contrário, o ensino tornar-se-á "inautêntico, palavreado vazio e inoperante" (p. 25). Esse ensino inautêntico, alienante e vazio só favorece a indisciplina e a falta de motivação por parte de educandos/as, não apenas no sistema educativo brasileiro, conforme elucida Shor.

\footnotetext{
${ }^{3}$ Grupo fundado e liderado por Miguel Nagib que visa negar a relação entre educação e política e, em nome da pretensa neutralidade da educação, vem buscando aprovação de projetos de lei municipais, estaduais e municipais que preconizam sanções a educadores/as que abordarem, em suas aulas, temas como gênero, sexualidade, orientação sexual, política, etc.
} 
STUCCHI, Mariza Pavan; SOUSA, Fabiana Rodrigues de. Assembleia de classe como espaço educativo de convivência, autonomia e problematização da realidade.

Uma das grandes crises dos EUA, neste momento, é a resistência dos estudantes ao currículo oficial. Em outras palavras, os professores e os administradores se recusam a mudar o currículo que aliena o estudante. A reação dos estudantes é recusar-se a trabalhar de acordo com o currículo oficial. A pedagogia oficial está motivando os estudantes contra o trabalho intelectual. Essa luta de poder pelo currículo levou as escolas e universidades a um impasse, que vários órgãos oficiais definiram, equivocadamente, como "mediocridade" estudantil. Eu chamo isto de "greve de desempenho" dos estudantes, que se recusam a estudar sob as condições sociais existentes (FREIRE; SHOR, 1986, p. 16).

A luta de poder pelo currículo também se verifica no sistema de ensino brasileiro, como bem descrevem Ribeiro e Alves (2018), sobretudo, com a chamada popularização do ensino superior no país que gerou o acesso massivo de jovens oriundos das camadas populares às instituições de ensino. Apesar do crescente acesso, tais jovens se deparam com inúmeras dificuldades para garantia de sua permanência, uma vez que muitas instituições de ensino superior ainda optam pela manutenção de seus conteúdos, procedimentos didáticos e pedagógicos sem considerar as especificidades dessas juventudes universitárias populares.

Em estudo que versa sobre as especificidades de jovens populares de um curso de Pedagogia, Eckhardt (2018) afirma que as histórias de vida e formação desses estudantes apresentam marcas decorrentes da subalternização, humilhação e silenciamento sofridos historicamente. Alicerçando-se na relação centro-periferia desenvolvida por Dussel (2006), Eckhardt (2018) salienta que é necessário repensar as epistemologias até então utilizadas nas universidades de modo a impulsionar o deslocamento do sentimento de humilhação e inadequação, comumente vivenciado por estudantes populares, para o processo de reconhecimento como periferia.

Sousa e Nascimento (2019, p. 773), em artigo que analisam as percepções de jovens cotistas de um curso de Engenharia Mecânica, complementam esse entendimento e destacam que o ingresso de estudantes populares, no ensino superior, "tem descortinado temas, experiências e condições existenciais, até pouco tempo, ignoradas nas universidades”. Essas marcas e temas precisam ser problematizados nas práticas docentes, possibilitando o questionamento e superação da matriz curricular monocultural, ainda vigente. Os princípios dialógicos da Educação Popular, notadamente, as contribuições do legado freireano configuram-se como caminho fértil para embasar essa problematização e alimentar uma educação como prática da liberdade, na qual a promoção da consciência crítica constitui-se não apenas como fim, mas também como metodologia de formação aliando a leitura da palavra à leitura de mundo. 
STUCCHI, Mariza Pavan; SOUSA, Fabiana Rodrigues de. Assembleia de classe como espaço educativo de convivência, autonomia e problematização da realidade.

Diante do exposto, é possível vislumbrar como a imposição de uma grade curricular monocultural - eurocêntrica, sexista, hetorenormativa e, por vezes, distante do mundo vida dos/as educandos/as - pode constituir-se como catalisadora de indisciplina e conflitos escolares, não apenas no ensino superior, mas em todas as modalidades de educação, culminando na alienação dos/as educandos/as. Há que se problematizar o grau de alienação dos educandos e educandas nos sistemas educativos, distinguindo o que é falta de motivação e o que é resistência, já que certas ações, sob a ótica de alguns educadores e educadoras, poderiam figurar como manifestações de indisciplina, enquanto para outros/as, poderiam ser interpretadas como iniciativas protagonizadas por educandos/as com vistas a refutar práticas e conteúdos escolares que tendem a negar ou inferiorizar a diversidade cultural e epistemológica da sociedade brasileira.

Essa estratégia de legitimação da superioridade cultural europeia teve reflexos na cultura escolar, que, por sua vez, atuou fortemente sobre as concepções de identidade e sobre o reconhecimento da diferenciação étnico-cultural de indivíduos e grupos. Kreutz conclui que, nas sociedades modernas, "a função da escola tem sido predominantemente a afirmação de uma etnia, de uma perspectiva cultural, em detrimento das demais". Assim, as hierarquias culturais, epistemológicas, étnico-raciais, foram reforçadas pela criação de ambientes escolares monoculturais e homogeneizantes, que abordam apenas uma perspectiva cultural, eurocêntrica, e prejudicam a formação de identidades positivas pelos distintos grupos que compõem a sociedade (OLIVEIRA et al. 2014, p. 116).

Destaca-se, então, a importância de um currículo escolar com propostas democráticas que propicie acesso e valorização a uma diversidade de culturas, conhecimentos e informações, favorecendo a discussão e construção de opiniões plurais sendo expressas e acolhidas por todos/as envolvidos/as no ato de educar. De acordo com esse princípio, educandos e educandas possuem papel ativo de construtores de significados e, por conseguinte, aprendem a ser leitores críticos da realidade na qual estão inseridos. Para isso, o papel dos/as educadores/as é fundamental, pois ao criarem oportunidades em que os/as educandos/as possam fazer escolhas e tomar decisões estarão possibilitando que os/as mesmos/as assumam responsabilidades e exercitem a autonomia no cotidiano escolar.

As contribuições advindas da obra de Freire reiteram o entendimento de que a democracia na escola se constitui a partir de experiências participativas e dialógicas e de uma educação crítica que estimule a ampliação dos conhecimentos e leitura de mundo, propiciando que educandos e educandas problematizem sua realidade e construam sua autonomia. Nesse cenário, a assembleia de classe pode constituir-se como mediação pedagógica importante para a formação 
STUCCHI, Mariza Pavan; SOUSA, Fabiana Rodrigues de. Assembleia de classe como espaço educativo de convivência, autonomia e problematização da realidade.

política-cidadã dos sujeitos. Nesta perspectiva, Araújo (2004) argumenta como as assembleias escolares podem figurar como espaços de vivência da constituição e prática da democracia na relação cotidiana da escola.

Para que o modelo de democracia seja justo e almeje a liberdade individual e coletiva, é necessário que a igualdade e a equidade sejam compreendidas como complementares. Ao mesmo tempo que a igualdade de direitos e deveres deve ser objetivada nas instituições sociais, não se deve perder de vista o direito e o respeito à diversidade, ao pensamento divergente. Esse princípio é uma das bases que sustentam as assembleias escolares (ARAÚJO, 2004, p. 12-13).

Assim, a assembleia de classe acontece como uma prática pedagógica democrática que engendra novas possibilidades para as resoluções coletivas de conflitos vivenciados no dia a dia escolar que, ao mesmo tempo, “[...] permite a construção psicológica, social, cultural e moral do próprio sujeito, em um movimento dialético em que o coletivo transforma e constitui cada um de nós, que, por nossa vez, transformamos e ajudamos na constituição dos espaços e relações coletivas" (ARAÚJO, 2008, p. 118).

Porém, a assembleia de classe só pode ocorrer em sua plenitude quando as escolas se comprometerem com uma concepção de educação que abarque as crianças, jovens e adultos como seres humanos integrais, que levam consigo uma bagagem de experiências e saberes e que precisam encontrar na escola um ambiente propício para o desenvolvimento de atividades comprometidas com o desvelamento de saberes de experiência e com a construção de valores e de princípios democráticos como a solidariedade, a cooperação, o diálogo e a autonomia.

De acordo com Larrosa-Bondía (2002), o sujeito da experiência é aquele que é transformado pelas experiências. Por sua vez, o saber da experiência é:

[...] o que se adquire no modo como alguém vai respondendo ao que vai lhe acontecendo ao longo da vida e no modo como vamos dando sentido ao acontecer do que nos acontece. No saber da experiência não se trata da verdade do que são as coisas, mas do sentido ou do sem-sentido do que nos acontece (p. 26-27).

As assembleias de classe apresentam-se, pois, como espaço viável para problematizar esses saberes de experiência construídos pelos/as educandos/as em suas relações entre si e com os/as educadores/as. Nelas, são discutidos os mais variados temas do contexto escolar, desse modo, elas figuram como "espaços de informação e de análise, de tomada de decisões e de organização, de solução de problemas e de construção de acordos” (PUIG et al., 2000, p. 161). 
STUCCHI, Mariza Pavan; SOUSA, Fabiana Rodrigues de. Assembleia de classe como espaço educativo de convivência, autonomia e problematização da realidade.

As assembleias de classes, além de se configurarem como espaço para elaboração e reelaboração das regras que regulam a convivência escolar "propiciam momentos para o diálogo, a negociação e o encaminhamento de soluções dos conflitos cotidianos. Dessa maneira, contribuem para a construção de capacidades psicomorais essenciais ao processo de construção de valores e atitudes éticas” (ARAÚJO, 2008, p. 118).

A formação nas assembleias de classe "deve visar ao desenvolvimento de competências para lidar com a diversidade e o conflito de ideias, com as influências da cultura e com os sentimentos e as emoções presentes nas relações do sujeito consigo mesmo e com o mundo à sua volta" (ARAÚJO, 2004, p. 15). Estimulando, desse modo, que educandos e educandas conversem sobre os assuntos de interesses do grupo, criem os combinados, desenvolvam a autonomia e promovam a democracia no ambiente escolar, contribuindo para a constituição de uma sociedade mais humanizada.

Para Araújo (2004), a pauta com os temas a serem discutidos na assembleia de classe deve ser construída durante a semana que antecede o encontro e sugere que, logo após a realização de uma, já se comece a planejar a pauta da seguinte. Os temas propostos não se restringem à abordagem de aspectos negativos e conflitivos da convivência escolar, mas também devem garantir que momentos prazerosos sejam apresentados como felicitações e conquistas propondose discussões de projetos futuros. Os temas procuram cumprir as funções previstas para as assembleias que consistem em informar e analisar o que acontece com a classe a fim de auxiliar nas decisões para a organização coletiva do grupo, a partir do diálogo e da cooperação. É necessário salientar que a discussão deve pautar-se pelos princípios da convivência, nas causas e consequências dos fatos ocorridos e não nas pessoas e, sendo assim, a regra e o encaminhamento final deverão apontar a postura da classe frente a tais ações.

Nesse sentido, a assembleia de classe pode ser percebida como prática democrática que fortalece a participação e promove o diálogo entre educadores/as e educandos/as, levando-os a uma compreensão mútua e possibilitando o sentimento de pertencimento à escola. Cria-se, assim, um ambiente favorável à troca de experiências entre os educadores/as e educandos/as o que pode contribuir com seu engajamento na busca pela superação das relações verticais.

A promoção de vínculos de pertencimento com a escola é importante, pois, como ressalta Aquino (1996), cada vez mais as escolas vêm recebendo um novo sujeito histórico, com outros 
STUCCHI, Mariza Pavan; SOUSA, Fabiana Rodrigues de. Assembleia de classe como espaço educativo de convivência, autonomia e problematização da realidade.

valores, outras experiências e vivências. As assembleias de classe tornam-se, pois, espaços relevantes para tentar entender e administrar coletivamente essa nova realidade, essas novas manifestações sociais. Do ponto de vista sócio-histórico o autor esclarece, ainda, que os conflitos escolares e a indisciplina podem ser interpretados como um sinal de resistência engendrando a "[...] produção de novos significados e funções, ainda insuspeitos, à instituição escolar" (AQUINO, 1996, p. 45).

Araújo (2004) defende que educadores e educadoras deveriam exercitar seu olhar e suas práticas para compreender a importância das relações interpessoais e dos conflitos, entendidos como “[...] matéria-prima para nossa constituição psíquica, cognitiva, ideológica e social” (p. 17). As práticas pedagógicas organizadas pelos educadores e educadoras são responsáveis por criar, diariamente, na sala de aula, momentos que possibilitem as diversas manifestações, em que as semelhanças e diferenças sejam percebidas, discutidas e comparadas, mobilizando-os na busca por alternativas e soluções para os conflitos, refletindo e dialogando sobre os próprios sentimentos e os dos/as colegas.

Em consonância com Araújo (2004), Aquino (1996) sugere que a "saída para a compreensão e o manejo da indisciplina na escola" está na relação educador/a-educando/a e diz que, “ambos são parceiros de um mesmo jogo" em que o rival é a "ignorância, a pouca perplexidade e o conformismo diante do mundo" (AQUINO, 1996, p. 50).

Freire (1993) também condena o conformismo e a mente fatalista e destaca que o conhecimento é muito importante para as mudanças. Neste contexto, aponta que a

[...] educação não é a alavanca da transformação social, mas sem ela essa transformação não se dá. Nenhuma nação se afirma fora dessa louca paixão pelo conhecimento, sem que se aventure, plena de emoção, na reinvenção constante de si mesma, sem que se arrisque criadoramente (p. 53).

As assembleias de classe podem figurar como práticas educativas viáveis, nas quais educadores/as e educandos/as se encontram para questionar o conformismo e fatalismo. De acordo com Freire (1993), educadores e educadoras como sujeitos históricos e transformadores têm que ter desejo e disponibilidade para educar e se educar, portanto, cabe-lhes a responsabilidade de instigar a curiosidade, o diálogo e a vontade de aprender. 
STUCCHI, Mariza Pavan; SOUSA, Fabiana Rodrigues de. Assembleia de classe como espaço educativo de convivência, autonomia e problematização da realidade.

\section{Assembleias de classe e a sistematização de experiências}

A prática da assembleia de classe ocorre, na escola em que a pesquisa foi realizada, desde 2011 com a participação de educandos/as do $6^{\circ}$ ao $9^{\circ}$ ano do Ensino Fundamental; contudo para a investigação foram consideradas especificamente as atividades desenvolvidas, no primeiro semestre de 2017, com duas turmas de oitavo ano do período matutino. A escola pertence à rede privada de ensino e está situada em uma cidade localizada no interior do estado de São Paulo.

Para a realização das assembleias de classe, na escola onde se desenvolveu a pesquisa, foi destinada uma sala específica com carteiras dispostas em círculos, um computador para a organização da ata dos encontros, um mural e uma lousa para o uso dos/as participantes. Para sistematizar a experiência com as assembleias de classe, no interior da referida escola, foi preciso compreender essa prática educativa como um processo social dinâmico que implica constantes mudanças e movimento, conforme advoga Jara-Holliday (2006).

A pesquisa teve seu percurso metodológico baseado no enfoque qualitativo que possibilitou observar as assembleias de classe no seu contexto natural.

Os investigadores qualitativos estabelecem estratégias e procedimentos que lhes permitam tomar em consideração as experiências do ponto de vista do informador. $\mathrm{O}$ processo de condução de investigação qualitativa reflete uma espécie de diálogo entre os investigadores e os respectivos sujeitos, dado estes não serem abordados por aqueles de uma forma neutra (BOGDAN; BIKLEN, 1994, p. 51).

Nesta direção, a sistematização da experiência da assembleia de classe foi elaborada com base na obra "Para sistematizar experiências", de Oscar Jara-Holliday (2006, p. 47), cuja concepção teórica e metodológica é a dialética, em que a realidade é entendida, ao mesmo tempo, como "una, mutante e contraditória porque é histórica; porque é produto da atividade transformadora, criadora dos seres humanos". É a partir da perspectiva dialética que "aproximamo-nos da compreensão dos fenômenos sociais desde o interior de sua dinâmica, como sujeitos participantes na construção da história, totalmente implicados de forma ativa em seu processo" (JARA-HOLLIDAY, 2006, p. 49). Segundo o autor, os processos que pertencem às práticas sociais e históricas são carregados de experiências vitais que levam consigo uma série de elementos inéditos e irrepetíveis, e que por isso, torna-se "tão apaixonante a tarefa de compreendê-las, extrair seus ensinamentos e comunicá-los" (JARA-HOLLIDAY, 2006, p. 21). 
STUCCHI, Mariza Pavan; SOUSA, Fabiana Rodrigues de. Assembleia de classe como espaço educativo de convivência, autonomia e problematização da realidade.

Além disso, a sistematização auxilia a entender e melhorar a própria prática porque permite aos educadores/as pensar sobre as diferentes etapas do processo educativo e fazer a diferenciação entre os elementos constantes dos ocasionais distinguindo a lógica das relações e das contradições. Para isso, é necessário aprender a compartilhar, de maneira crítica, os resultados do processo como modo de confrontar as aprendizagens mútuas e tecer um novo olhar para as próprias experiências. Do ponto de vista de Jara-Holliday (2006, p. 34), “isto fará com que tenhamos critérios orientadores válidos que permitam transformar e melhorar nossas próprias práticas e inseri-las dentro de um processo coletivo que as transcendam e por isso lhe dê sentido histórico."

No processo de sistematização há uma sustentação filosófica e teórica que incentiva um diálogo entre os saberes, possibilitando novos conhecimentos a partir dos já consolidados. O exercício de sistematização requer rigor na formulação de categorias, na classificação e ordenação de elementos empíricos, na realização de análise e síntese, indução e dedução. A sistematização contribui para a formação, pois permite orientar a prática a sua transformação.

Para sistematização das assembleias de classe foram empregados os seguintes procedimentos metodológicos: registro em diário de campo e atas das assembleias.

O diário de campo foi um rico instrumento para as anotações e descrições do vivido contribuindo para a compreensão do que aconteceu durante a pesquisa. Os registros em diário de campo permitiram recuperar a memória sobre a experiência vivida e ampliar a dimensão do que ocorreu confirmando a importância de "[...] um aprofundamento que procure ler nos olhos daqueles que vivem o acontecimento, para além de apenas descrevê-los” (LIMA, 2002, p. 149). $\mathrm{O}$ aspecto mais importante do diário de campo é “[...] que o diálogo entre o observador e a realidade observada se amplia e se aprofunda quando o pesquisador se obriga à melhor percepção possível para melhor poder registrar" (WHITAKER, 2002, p. 124). O áudio de algumas assembleias foi gravado e, posteriormente, transcrito para ampliar o registro em diário de campo.

Nas atas das assembleias foram registrados os temas escolhidos para cada encontro, além da descrição de como aconteceu a discussão de cada tema, dos encaminhamentos e das felicitações de maneira resumida. É uma etapa fundamental no processo, pois permite que todas as decisões, regras e encaminhamentos fiquem gravados e, se necessário, sejam consultados posteriormente. 
STUCCHI, Mariza Pavan; SOUSA, Fabiana Rodrigues de. Assembleia de classe como espaço educativo de convivência, autonomia e problematização da realidade.

Como resultado desse esforço analítico de sistematizar a experiência das assembleias de classe, foram identificadas cinco categorias que serão detalhadas, a seguir, quais sejam: elaboração coletiva de regras, desenvolvimento da autonomia, relação educador/a-educando/a, percepções dos/as educandos/as sobre a assembleia de classe e saberes de experiência.

\section{a) Elaboração coletiva de regras}

Para a construção da convivência no espaço escolar, com base nas relações democráticas, é necessário aprender a lidar com os conflitos, a respeitar-se e respeitar o outro, escutar e dialogar, ou seja, compreender que as atitudes tomadas refletem nas interações com os colegas e nas relações com todos que fazem parte da convivência diária, o que requer o estabelecimento coletivo de regras.

Tognetta e Vinha (2007) afirmam que mais importante do que os problemas em si é a forma de enfrentá-los, isso porque as regras tornam-se significativas quando há discussões coletivas entre os pares oportunizando ações cooperativas em vez de imposições. Neste sentido, é importante ponderar a necessidade de as regras de convivência no cotidiano escolar serem construídas com os/as educandos/as de forma a colaborar com o entendimento de que as mesmas passem a ser cumpridas no uso da consciência autônoma, condição esta fundamental ao desenvolvimento da autonomia moral.

Puig et al. (2000) apontam duas vertentes para a construção das normas e do respeito às regras na escola. A vertente da heteronomia, quando as normas existentes são estabelecidas pelos/as educadores/as, no cotidiano escolar, e chegam aos educandos/as de forma pronta e definida. E a vertente da autonomia, que ocorre quando essas normas e regras são discutidas e assimiladas pelos/as educandos/as e, caso seja necessário, reformuladas, possibilitando que sejam respeitadas. As assembleias de classe figuraram como espaço-tempo fundamental para discussão e problematização das regras implementadas na escola.

\section{b) Desenvolvimento da autonomia}

Do ponto de vista piagetiano, o desenvolvimento moral está ligado à maneira como as relações e interações acontecem no ambiente em que o/a adolescente está inserido/a. Para falar do 
STUCCHI, Mariza Pavan; SOUSA, Fabiana Rodrigues de. Assembleia de classe como espaço educativo de convivência, autonomia e problematização da realidade.

desenvolvimento da autonomia moral, segundo Piaget (1986), é necessário apontar a autonomia e a reciprocidade como condição para se respeitar e ser respeitado, pois é por meio da interação social que ocorre a internalização das regras e, por conseguinte, alcança-se a autonomia moral.

Na perspectiva de Freire (1987), há que se considerar a valorização da cultura decorrente da práxis e do diálogo que se fundam em diferentes visões de mundo construídas pelos/as adolescentes. Com a problematização da realidade torna-se possível a construção da consciência crítica em que são contempladas a criatividade e a imaginação, antecipando-se a um mundo mais justo e humanizado. $\mathrm{O}$ autor esclarece que tanto a dignidade quanto a identidade do educando e educanda têm de ser respeitadas, pois do contrário, o conhecimento se tornará inautêntico e inoperante impedindo que ocorram as transformações. Para isso, Freire (1987) afirma que o educador/a terá que se dedicar com vontade, disponibilidade e rigor metódico de forma a possibilitar a construção da consciência crítica da realidade e que a autonomia deve ser conquistada e erigida a partir das vivências. Portanto, a escola deve propiciar contextos formativos coletivos para que educandos e educandas possam se fazer autônomos.

\section{c) Relação educador/a-educando/a}

Para que a educação atinja seu objetivo de formar os sujeitos para a autonomia, é necessário que as relações entre educadores/as e educandos/as e entre educandos/as e seus pares sejam muito valorizadas e cuidadas dentro do espaço escolar, no qual há uma imensa diversidade cultural e social. É também nesse espaço que transcorrem os aprendizados da vida e a compreensão sobre o mundo em que se vive balizados pelo diálogo, reflexão e participação. Por isso, o papel de mediação dos educadores/as é de extrema importância para fomentar a humanização dos sujeitos envolvidos, formando e transformando ideias e pensamentos. Portanto, a aprendizagem da cidadania e da convivência democrática decorre da compreensão do pertencimento a uma coletividade e que por meio desse encontro de pessoas diferentes é possível crescer, quando se respeita o tempo e o espaço de cada um/a.

\section{d) Percepções dos/as educandos/as sobre a assembleia de classe:}

É pela práxis (ação-reflexão-ação) que os participantes da assembleia de classe vão, aos poucos, desenvolvendo as habilidades necessárias à construção da autonomia e de uma 
STUCCHI, Mariza Pavan; SOUSA, Fabiana Rodrigues de. Assembleia de classe como espaço educativo de convivência, autonomia e problematização da realidade.

convivência escolar mais harmônica, prazerosa e democrática. Dentre essas habilidades destacam-se a construção da argumentação, capacidade de ouvir os outros, conhecer visões de mundo diferentes, aprender a respeitar o outro, etc. Uma participante da pesquisa frisa que a importância da assembleia de classe não se reduz a solucionar conflitos, mas em aprender como discuti-los e encaminhá-los, já que nem todos os problemas possuem uma solução imediata.

A assembleia é muito importante, tanto para ver o modo de pensar de outras pessoas sobre a mesma situação como para uma maior formação de caráter. Nem sempre algo que discutimos na assembleia é resolvido mas, buscamos ver os dois lados do problema [...]. É uma forma de aumentar a nossa capacidade de argumentar, aumentar nosso respeito para com as outras pessoas [...].

\section{e) Saberes de experiência}

Larrosa-Bondía (2002, p. 20) enaltece a força das palavras para as nossas vidas e diz que os nossos pensamentos são determinados pelas palavras e que são eles que dão sentido ao que somos e ao que nos toca. Afirma que, por meio das palavras, se torna possível nomearmos o que vemos e o que sentimos e como vemos e sentimos o que nomeamos partindo da "convicção de que as palavras produzem sentido, criam realidades e, às vezes, funcionam como potentes mecanismos de subjetivação.”

O autor aponta que é necessário que o sujeito da experiência esteja disponível e aberto para parar nos tempos atuais, nesses tempos agitados e repletos de informações para pensar, escutar, sentir da maneira mais intensa possível, suspender o juízo e o automatismo das ações, cultivar a atenção e a delicadeza, falar sobre o que nos acontece e cultivar o encontro com o outro, escutando com paciência, com tempo e espaço. Afirma que somente o sujeito da experiência está aberto à sua própria transformação porque a experiência quando nos toca ou nos acontece, nos forma e nos transforma.

Nessa pesquisa, identificou-se que por meio da participação em assembleias de classe, educandas e educandos do oitavo ano desenvolvem alguns saberes de experiência, quais sejam: realizar as próprias escolhas e a se responsabilizar por elas, expressar suas ideias de maneira organizada e respeitosa, exercitar o diálogo, aprender a ouvir e tentar se colocar no lugar do outro, lidar com conflitos cotidianos buscando coletivamente tomar decisões para superá-los, dentre outros. 
STUCCHI, Mariza Pavan; SOUSA, Fabiana Rodrigues de. Assembleia de classe como espaço educativo de convivência, autonomia e problematização da realidade.

Ao demonstrarem consciência da diversidade de opiniões sobre os temas discutidos e o respeito à diversidade de pensamentos, conseguindo ouvir o outro ao tempo que reconhecem a si mesmos, esses/as adolescentes podem pensar de forma reflexiva, que segundo Piaget (1986) favorece a formação de novos esquemas de pensamento, viabilizando novo equilíbrio e, gradativamente, atingindo a autonomia moral. Dessa forma, compreendemos que a capacidade dos educandos e educandas de agirem sobre o meio e transformá-lo, no sentido emancipatório de que nos fala Freire (1987), amplia-se quando participam de práticas educativas dialógicas e democráticas, como a assembleia de classe.

\section{Considerações}

O diálogo tem uma das funções mais importantes na assembleia de classe, uma vez que os temas propostos e os que surgem durante os encontros impulsionam o trabalho paralelo de um conjunto de conteúdos procedimentais (empatia, diálogo, autorregulação) e de valores (respeito, cooperação, valorização da diversidade) que devem ser explorados pelos educadores/as como um auxílio para chegarem às soluções para cada situação apresentada (Puig et al., 2000).

Para Freire (1987), quando o sujeito passa a interpretar os problemas e a realidade em que vive, adquire consciência crítica do significado de suas ações e busca a transformação desse meio em que vive e de si próprio.

Como resultado da sistematização foi possível perceber que a assembleia de classe pode configurar-se como espaço-tempo de diálogo e reflexão sobre a realidade. Já que, ao tomar parte dela, educandos/os e educadores/as vão exercitando a escuta atenta e o respeito às diversas opiniões, aprendem a refletir sobre sua postura, a pensar em como organizar e expor seus pensamentos e argumentos, bem como, a construir coletivamente possibilidades de superar os conflitos vividos em ambientes escolares. Destaca-se o diálogo como fundamental nesse processo por viabilizar as discussões e as necessárias problematizações acerca da realidade vivida.

A participação nas assembleias promove o diálogo entre educandos/as e educadores/as. Todavia, a consolidação de uma educação democrática e para autonomia exige que a dialogicidade e a problematização sejam tomadas, de forma mais ampla, como princípios da gestão escolar, perpassando às demais práticas desenvolvidas na escola, tais como planejamento pedagógico, atividades avaliativas, etc. O que implica no reconhecimento da importância de 
STUCCHI, Mariza Pavan; SOUSA, Fabiana Rodrigues de. Assembleia de classe como espaço educativo de convivência, autonomia e problematização da realidade.

fomentar espaços-tempo, como as assembleias de classe, para reflexão coletiva acerca de temas, regras e convivência escolar; porém sem perder de vista que tal reflexão deve se vincular às realidades vivenciadas por educandos e educandas para além dos muros da escola e, portanto, deve abarcar marcadores culturais, geracionais, de classe, de raça/etnia, de gênero, de orientação sexual, etc.

O caminhar na busca pela efetivação da educação democrática reclama a reorganização do trabalho escolar e a reconstrução do currículo escolar, assumindo as tensões e conflitos envoltos nesse processo. Dessa forma, a problemática da violência e da indisciplina, no âmbito escolar, não pode ser tomada como situação-limite instransponível, mas sim compreendida como "pedrasonho" capaz de gerar novos significados e temas-geradores a serem problematizados, de modo a alimentar a esperança de uma educação humanizadora que se concretize como prática da liberdade.

Espera-se que as considerações e reflexões tecidas nessa investigação colaborem com processos de avaliação, análise e reconstrução das assembleias de classe. Ao desvelar as potencialidades dessa prática educativa, buscou-se suscitar contribuições a fim de estimular o

debate com vistas à superação das dificuldades encontradas e proposição de atividades que favoreçam a convivência, o diálogo e a autonomia dos/as educandos/as.

\section{Referências}

AQUINO, Julio Groppa. A desordem na relação professor-aluno: indisciplina, moralidade e conhecimento. In: AQUINO, Julio Groppa (org.). Indisciplina na escola: alternativas teóricas e práticas. São Paulo: Summus, 1996. p. 39-55.

ARAÚJO, Ulisses F. Resolução de conflitos e assembleias escolares. Cadernos de Educação, Pelotas, v. 31, p. 115131, jul./dez. 2008.

ARAÚJO, Ulisses F. Assembleia escolar: um caminho para a resolução de conflitos. São Paulo: Moderna, 2004.

BOGDAN, Robert C.; BIKLEN, Sari K. Investigação qualitativa em educação. Portugal: Porto Editora, 1994.

CHARLOT, Bernard. A violência na escola: como os sociólogos franceses abordam essa questão. Sociologias, Porto Alegre, n. 8, p. 432-443, dez. 2002.

DUSSEL, Enrique. Filosofía de la liberación. Bogotá: Nueva América, 1996.

ECKHARDT, Fabiana. As classes populares no curso de Pedagogia descobrindo-se periferia. Revista Ciências da Educação, Americana, v. 10, n. 41, p. 149-162, out. 2018.

ESTRELA, Maria Teresa. Relação pedagógica, disciplina e indisciplina na aula. 4. ed. Porto: Porto Editora, 2002. FREIRE, Paulo. Pedagogia da autonomia: saberes necessários à prática educativa. 25. ed. São Paulo: Paz e Terra, 1996. 
STUCCHI, Mariza Pavan; SOUSA, Fabiana Rodrigues de. Assembleia de classe como espaço educativo de convivência, autonomia e problematização da realidade.

FREIRE, Paulo. Professora sim, tia não: cartas a quem ousa ensinar. São Paulo: Editora Olho d'Água, 1993.

FREIRE, Paulo. Pedagogia da esperança: um reencontro com a pedagogia do oprimido. Rio de Janeiro: Paz e Terra, 1992.

FREIRE, Paulo. Pedagogia do oprimido. 17. ed. Rio de Janeiro: Paz e Terra, 1987.

FREIRE, Paulo; SHOR, Ira. Medo e ousadia: o cotidiano do professor. Rio de Janeiro: Paz e Terra, 1986.

GARCIA, Joe. Indisciplina na escola: questões sobre mudança de paradigma. Contra-Pontos, Itajaí, v. 8, n. 3, p. 367-380, set./dez. 2008.

GARCIA, Joe. Indisciplina, incivilidade e cidadania na escola. ETD - Educação Temática Digital, Campinas, v. 8, n. 1, p. 10-32, dez. 2006.

GARCIA, Joe; TOGNETTA, Luciene R. P.; VINHA, Telma P. Indisciplina, conflitos e bullying na escola. Campinas: Mercado de Letras, 2013.

JARA-HOLLIDAY, Oscar. Para sistematizar experiências. 2. ed. Brasília: MMA, 2006.

KRAMER, Sonia. Por entre as pedras: arma e sonho na escola. São Paulo: Ática, 1994.

LAROSSA-BONDÍA, Jorge. Nota sobre experiência e o saber de experiência. Rev. Bras. Educ., Rio de Janeiro, n. 19, p. 20-28, jan./abr. 2002.

LEME, Maria Isabel S. Convivência, conflitos e educação nas escolas de São Paulo. São Paulo: ISME, 2006.

LIMA, Helton Souto. O diário de campo e sua relação com o olhar aprofundado sobre o espaço rural. In.

WHITAKER, Dulce C. A. Sociologia rural: questões metodológicas emergentes. Presidente Venceslau: Letras à Margem, 2002. p.143-149.

OLIVEIRA, Maria Waldenez et al. Pesquisando processos educativos em práticas sociais: reflexões e proposições teórico-metodológicas. In: OLIVEIRA, Maria W.; SOUSA, Fabiana R. (orgs). Processos educativos em práticas sociais: pesquisas em educação. São Carlos: EdUFSCar, 2014. p. 113-141.

PIAGET, Jean. Seis estudos de psicologia. 14. ed. Rio de Janeiro: Forense-Universitária, 1986.

PUIG, Josef M. et al. Democracia e participação escolar: propostas de atividades. São Paulo: Moderna, 2000.

RAMOS, Moacyr S.; SANTORO, Ana Cecília S. Pensamento freireano em tempo de escola sem partido. InterAção, Goiânia, v. 42, n. 1, p. 140-158, jan./abr. 2017.

REGO, Teresa C. R. A indisciplina e o processo educativo: uma análise na perspectiva vygotskiana. In: AQUINO, Julio Groppa. (org). Indisciplina na escola: alternativas teóricas e práticas. São Paulo: Summus, 1996. p. 83-101.

RIBEIRO, Adalberto C.; ALVES, Maria Natália C. Juventudes universitárias populares e educação freireana: reflexões sociológicas. Quaestio, Sorocaba, v. 20, n. 2, p. 305-325, ago. 2018. Disponível em: http://periodicos.uniso.br/ojs/index.php/quaestio/article/view/3335/2946. Acesso em: 10 fev. 2019.

SOUSA, Fabiana R.; NASCIMENTO, Ilca F. Lei de cotas e promoção da justiça social: percepções de estudantes cotistas de um instituto federal. Revista Espaço Pedagógico, Passo Fundo, v. 26, n. 3, p. 758-776, set./dez. 2019.

TOGNETTA, Luciene R. P.; VINHA, Telma P. Quando a escola é democrática: um olhar sobre as práticas das regras e assembleias na escola. Campinas: Mercado das Letras, 2007.

VINHA, Telma P. O educador e a moralidade infantil: uma visão construtivista. Campinas: Mercado das Letras; São Paulo: FAPESP, 2000.

WHITAKER, Dulce C. A. Apresentando os textos. In. WHITAKER, Dulce C. A. Sociologia rural: questões metodológicas emergentes. Presidente Venceslau: Letras à Margem, 2002. p. 123-130. 